\title{
The latest trend in neuromuscular monitoring: return of the electromyography
}

\section{Wonjin Lee ${ }^{1,2}$}

Received February 14, 2021

Accepted February 21, 2021

\section{Corresponding author}

Wonjin Lee, M.D.

Department of Anesthesiology and

Pain Medicine, Busan Paik Hospital,

Paik Institute for Clinical Research,

Inje University College of Medicine, 75

Bokji-ro, Busanjin-gu, Busan 47392,

Korea

Tel: 82-51-890-6520

Fax: 82-51-898-4216

E-mail: 2wonjin@naver.com
${ }^{1}$ Department of Anesthesiology and Pain Medicine, Busan Paik Hospital, ${ }^{2}$ Paik Institute for Clinical Research, Inje University College of Medicine, Busan, Korea
To reduce the risk of residual neuromuscular blockade, neuromuscular monitoring must be performed. Acceleromyography (AMG)-based neuromuscular monitoring was regarded as "clinical gold standard" and widely applied. However, issues related to patient's posture and overestimation of train-of-four ratio associated with AMG-based neuromuscular monitoring have increased. Recently, electromyography (EMG)-based neuromuscular monitoring is receiving renewed attention, since it overcomes AMG's weaknesses. However, both AMGbased and EMG-based systems are useful when certain considerations are followed. Ultimately, to assure the patient's good outcomes, the choice of monitoring system is not as important as the monitoring itself, which should be always implemented in such patients.

Keywords: Delayed emergence from anesthesia; Electromyography; Neuromuscular blocking agents; Neuromuscular monitoring.

\section{INTRODUCTION}

A 2015 review [1] selected the two most relevant articles among 20 anesthesiology fields, and in the field of neuromuscular blockers, the first was a report on the clinical use of curare from 1942 [2], while the second was a study on the risk of surgery and anesthesia from 1954 [3], which first reported the risk of neuromuscular blockers. Considering these evidences, the use of neuromuscular blockers could be interpreted as a double-edged sword that facilitates anesthesia and surgery, but is simultaneously associated with increased postoperative complications and mortality due to residual neuromuscular blockade. Despite developments such as reduction of the duration of action of neuromuscular blockers and the use of neuromuscular reversal agents, postoperative complications and mortality due to residual neuromuscular blockade remain a problem [4-6].

The development of neuromuscular blockers and reversal agents resulted in that of neuromuscular monitoring methods for the residual neuromuscular blockade. The first peripheral nerve stimulator was developed in 1958 [7], and thereafter, mechanomyography (MMG)- and electromyography (EMG)-based measuring methods were developed. However, these devices were bulky and complicated to use, so they did not become widely used. In 1988, acceleromyography (AMG) was first introduced [8,9], and this device based on this principle started to be widely used clinically, as the equipment became portable and easier to use. In the following decades, AMG-based neuromuscular monitoring equipment was regarded as "clinical gold standard" and widely distributed. Recently, however, owing to developments in surgical techniques such as laparoscopy and robotic surgery, neuromuscular monitoring has decreased because access to the patient's arm is difficult in such surgical conditions. In addition, owing to issues such as overestimation of train-of-four (TOF) ratio in AMGbased equipment, EMG-based neuromuscular monitoring is back in the spotlight. In this article, we review the trends

This is an Open Access article distributed under the terms of the Creative Commons Attribution Non-Commercial License (http://creativecommons.org/licenses/by-nc/4.0) which permits unrestricted non-commercial use, distribution, and reproduction in any medium, provided the original work is properly cited.

Copyright (C) the Korean Society of Anesthesiologists, 2021 
of recent neuromuscular monitoring equipment use through a comparison between the most widely distributed AMG-based and recently developed EMG-based equipment.

\section{ACCELEROMYOGRAPHY AND ELECTROMYOGRAPHY}

Neuromuscular monitoring equipment measures the muscle's contractile "force" following electrical nerve stimulation. Therefore, the classical standard neuromuscular monitoring equipment was MMG-based, which directly measured contractile "force," and different types of neuromuscular monitoring equipment are compared with it to determine their reliability [10]. However, since MMGbased equipment is bulky and difficult to set up, it is not used for clinical purposes.

The AMG-based method measures muscle acceleration based on the fact that, according to Newton's second law of motion "Force $=$ mass $\times$ acceleration," force and acceleration are proportional [9]. AMG-based measurements were correlated well with MMG-based measurements, and showed reliable results [11,12]; thus, it is widely used. Until the recent EMG-based devices were released around 2018, most clinical neuromuscular monitoring equipment available was AMG-based. In particular, the TOF-Watch (Organon, Ireland) series is widely used worldwide, amounting for $91 \%$ of all neuromuscular monitoring devices according to a 2017 Danish survey [13].

The EMG-based method measures the compound muscle action potential (CMAP) and focuses on the fact that the CMAP is proportional to the muscle's contractile force. The EMG-based method was also correlated well with the MMG-based method [14,15], but some reports found minor dissimilarities $[9,16,17]$. However, recently neuromuscular monitoring consensus concluded that the EMGbased methods are reliable enough to be exchangeable with MMG [18]. Until 2018, only one EMG-based equipment, the Datex-Ohmeda NMT module (GE Healthcare, UK) was clinically available, so it was not commonly used. Recently, the TwichView (Blink Device Company, USA) and TetraGraph (Senzime AB, Sweden) have been released and the use of EMG-based monitoring has been increasing.

\section{AMG-BASED EQUIPMENT}

Since AMG-based equipment measures muscle acceleration, it is very sensitive to movement. Therefore, the immobilization of all related muscles and structures except for the muscle to be measured is essential (for example, immobilizing the arm and 2nd-5th finger during ulnar nerve stimulation) for accurate measurement [10]. In addition, the muscles to be measured (for example, the adductor pollicis during ulnar nerve stimulation) should be able to move freely. If the movement of the target muscle is restricted by the surgical cloth or by fixing the arm to the body, an accurate measurement cannot be obtained [10]. According to a Danish survey, $75 \%$ of respondents experienced difficulties $>1$ out of four times when using a neuromuscular monitor, and $41 \%$ considered that these were caused by TOF fluctuation [13]. Therefore, for accurate AMG-based equipment use, removing obstacles that hinder the target muscle movement and avoiding movement of the surgical participant, which affects the measurement, are two important points.

Additionally, AMG-based equipment tends to overestimate TOF ratio more than MMG- or EMG-based methods, with a reported TOF ratio $10-20 \%$ higher than with the other methods [19-21]. To avoid this, when using AMG-based equipment it is recommended to "normalize" the TOF ratio according to the baseline value. For example, if the baseline TOF ratio is 1.1 on the AMG-based equipment, all measured TOF ratios should be divided by 1.1. If the TOF ratio on the monitor is 0.9 , the normalized value is $0.9 / 1.1$ $=0.82$, which means that recovery has not yet been achieved. However, in the clinical field, it is difficult to normalize each measurement, so for convenience, when using AMG-based equipment, TOF is generally considered to be $10 \%$ higher, and the criterion for neuromuscular recovery is not $>0.9$, but rather $>1.0[22,23]$.

There are some considerations when using TOF-Watch, the most widespread AMG-based equipment. There are three versions of TOF-Watch: TOF-Watch, TOF-Watch S, and TOF-Watch SX. The first two display values up to only 1.0, even when measured TOF ratios are $>1.0$, so they are not recommended for research requiring accurate measurements because normalization is impossible [10].

Since the accelerometer in TOF-Watch recognizes only unidirectional (front-back) acceleration [24], accurate measurements can only be performed when the sensor direction matches the muscle movement. TOF-scan (Drager 
Technologies, Canada), which compensates for this problem by a 3D-accelerometer to measure acceleration in all directions enables more accurate measurements [24].

\section{RETURN OF THE ELECTROMYOGRAPHY}

In recent years, the use of laparoscopic and robotic surgery has increased. Accordingly, to secure free movement space around the patient, the patient's arms are often attached to their bodies. In such postures, accurate measurements cannot be performed with AMG-based equipment. Although the patient's arm can be accessible for neuromuscular monitoring during anesthesia induction or recovery, monitoring cannot be properly performed during surgery. Sixteen percent of respondents to a survey reported difficulties due to the patient's arm position when using AMG-based equipment [13]. Conversely, EMG-based equipment has been reported to be less affected by the arm's position [25], and accurate measurement is possible even if the target muscle movement is restricted [18]. Therefore, new EMG-based monitoring equipment has been developed and its usage gradually increased owing to this recent surgical trend. Another advantage of current models is that, while previous EMG devices required attaching five electrodes and connecting complex lines, now they only require one integrated elec- trode. Furthermore, overestimation, a major problem of AMG, is not an issue in EMG, which can be used without normalization [26,27].

Recent research has focused on the increasing use of recent EMG-based equipment (Table 1). Bowdle et al. [27,28] reported that the TOF ratio from TwichView was correlated more with MMG-based equipment than with AMG-based equipment, and that TOFs were more sensitive and accurate with MMG-based equipment than with AMG equipment. In a comparative study between TwitchView and the Datex-Ohmeda NMT module, the only previous EMG device, TwitchView showed more reliable TOF counts [29]. Nemes et al. [30] evaluated whether TetraGraph would reduce pain during nerve stimulation owing to the larger contact area of the nerve stimulation electrode, but they showed no difference in pain scores compared to TOFWatch.

In summary, recently released EMG-based devices are expected to continue to increase in use because of their accurate measurement and the solution to the issues of AMG-based equipment: the need to normalize overestimated TOF values and the perioperative usage limitation by the patient's posture.

Table 1. The Study of the Recently Launched Electromyography-based Devices

\begin{tabular}{|c|c|c|c|c|c|}
\hline Study & $\begin{array}{c}\text { Study } \\
\text { population (n) }\end{array}$ & Comparison groups & Comparison target & Result & Conclusion \\
\hline Bowdle et al. [27] & 43 & $\begin{array}{l}\text { MMG } \\
\left.\text { AMG (Stimpod }{ }^{\mathrm{TM}}\right) \\
\left.\text { EMG (TwichView }{ }^{\mathrm{TM}}\right)\end{array}$ & TOF ratio & $\begin{array}{l}\text { Mean difference: } \\
4.7 \text { (EMG vs. MMG) } \\
14.9 \text { (AMG vs. EMG) }\end{array}$ & $\begin{array}{l}\text { EMG most closely resemble MMG } \\
\text { assessment of neuromuscular block- } \\
\text { ade }\end{array}$ \\
\hline Bowdle et al. [28] & 46 & $\begin{array}{l}\text { Palpation } \\
\text { MMG } \\
\text { AMG (Stimpod }{ }^{\mathrm{TM}} \text { ) } \\
\left.\text { EMG (TwichView' }{ }^{\mathrm{TM}}\right)\end{array}$ & TOF count & $\begin{array}{l}\text { Substantial agreement with } \\
\text { palpation (kappa): } \\
0.8 \text { (EMG) } \\
0.67 \text { (MMG) } \\
0.63 \text { (AMG) }\end{array}$ & $\begin{array}{l}\text { AMG frequently underestimated TOF } \\
\text { count in comparison with EMG }\end{array}$ \\
\hline Bussey et al. [29] & 5 & $\begin{array}{l}\text { Palpation } \\
\text { EMG (TwichView'TM) } \\
\text { EMG (E-NMT module) }\end{array}$ & TOF count & $\begin{array}{l}\text { E-NMT > TwichView for } 59 \% \\
\text { data. } \\
\text { 70\% of TwichView data, } \\
\text { 30\% of E-NMT data were } \\
\text { identical with palpation data. }\end{array}$ & $\begin{array}{l}\text { The E-NMT may overestimate the train- } \\
\text { of-four count }\end{array}$ \\
\hline Nemes et al. [30] & 135 & $\begin{array}{l}\left.\text { AMG (TOF-Watch }{ }^{\mathrm{TM}}\right) \\
\text { EMG (Tetragraph }\end{array}$ & Pain score (VNRS) & $\begin{array}{l}\text { Median score (EMG:AMG): } \\
\text { 2:2 (20 mA) } \\
\text { 3:3 (30 mA) } \\
5: 5(40 \mathrm{~mA}) \\
5: 6(50 \mathrm{~mA})\end{array}$ & $\begin{array}{l}\text { Two devices caused the same level of } \\
\text { discomfort }\end{array}$ \\
\hline
\end{tabular}

TOF: train-of-four, EMG: electromyography, MMG: mechanomyography, AMG: acceleromyography, VNRS: verbal numeric rating scale. TwichView ${ }^{\text {TM }}$ is the trademark of Blink Device Company (USA). Tetragraph ${ }^{\mathrm{TM}}$ is the trademark of Senzime $\mathrm{AB}$ (Sweden). Stimpod ${ }^{\mathrm{TM}}$ is the trademark of Xavant Technology (South Africa). TOF-Watch ${ }^{\mathrm{TM}}$ is the trademark of Organon (Ireland). E-NMT module is a product of GE Healthcare (USA). 


\section{ELECTROMYOGRAPHY OR ACCELEROMYOGRAPHY?}

Since 2010, international guidelines require neuromuscular monitoring when using neuromuscular blockers [31]. In Korea, in order to improve the quality of anesthesia, the National Health Insurance Service initiated the Anesthetic Quality Evaluation in 2018. Neuromuscular monitoring has been included in this evaluation, and numerous medical institutions have started to pay attention to neuromuscular monitoring. Until now, the Korean Neuromuscular Research Society conducted several surveys on neuromuscular monitoring use, but the rates of neuromuscular monitoring equipment use were low: $16.7 \%$ (2008), 24.7\% (2013), and $39.7 \%(2018)[32,33]$. Currently, the use of neuromuscular monitoring is expected to be increased due to the Anesthetic Quality Evaluation, but the use rate is still expected to be low.

The best neuromuscular monitoring device is that with high measurement accuracy and that is easy to use. The recently released EMG-based equipment not only provide more reliable measurements than AMG-based equipment $[27,28]$, but also increase the usability by means of a disposable integrated electrode. Consequently, we expect that EMG-based equipment will eventually replace AMG-based equipment in the neuromuscular monitoring equipment market. However, AMG-based equipment, which is currently widely used, can be as good a device as EMG-based equipment if properly used. For proper and accurate AMGbased equipment use, anesthesiologists need to pay attention to immobilization of the related structure and secure free movement of the target muscle, and keep in mind that the reported TOF ratio is overestimated. Ultimately, the choice of monitoring system is not as important as the monitoring itself, which should be always implemented.

\section{CONCLUSION}

Neuromuscular monitoring must be performed to reduce the risk of residual neuromuscular blockade. When using AMG-based neuromuscular monitoring devices, it is necessary to consider immobilization of the measurement site and free movement of the target muscle, and be aware that the TOF ratio is overestimated. Newly developed EMG-based devices are recommended because they provide accurate measurements and have few limitations.

\section{CONFLICTS OF INTEREST}

No potential conflict of interest relevant to this article was reported.

\section{DATA AVAILABILITY STATEMENT}

Not applicable.

\section{ORCID}

Wonjin Lee, https://orcid.org/0000-0002-6240-7370

\section{REFERENCES}

1. Barash P, Bieterman K, Hersey D. Game changers: the 20 most important anesthesia articles ever published. Anesth Analg 2015; 120: 663-70.

2. Griffith HR, Johnson GE. The use of curare in general anesthesia. Anesthesiology 1942; 3: 418-20.

3. Beecher HK, Todd DP. A study of the deaths associated with anesthesia and surgery: based on a study of 599, 548 anesthesias in ten institutions 1948-1952, inclusive. Ann Surg 1954; 140: 2-35.

4. Grosse-Sundrup M, Henneman JP, Sandberg WS, Bateman BT, Uribe JV, Nguyen NT, et al. Intermediate acting non-depolarizing neuromuscular blocking agents and risk of postoperative respiratory complications: prospective propensity score matched cohort study. BMJ 2012; 345: e6329.

5. Kirmeier E, Eriksson LI, Lewald H, Jonsson Fagerlund M, Hoeft A, Hollmann M, et al. POPULAR Contributors. Post-anaesthesia pulmonary complications after use of muscle relaxants (POPULAR): a multicentre, prospective observational study. Lancet Respir Med 2019; 7: 129-40.

6. Saager L, Maiese EM, Bash LD, Meyer TA, Minkowitz H, Groudine S, et al. Incidence, risk factors, and consequences of residual neuromuscular block in the United States: the prospective, observational, multicenter RECITE-US study. J Clin Anesth 2019; 55: 33-41.

7. Christie TH, Churchill-Davidson HC. The St. Thomas's Hospital nerve stimulator in the diagnosis of prolonged apnoea. Lancet 1958; 1: 776.

8. Jensen E, Viby-Mogensen J, Bang U. The accelograph: a new neuromuscular transmission monitor. Acta Anaesthesiol Scand 1988; 32: 49-52.

9. Viby-Mogensen J, Jensen E, Werner M, Nielsen HK. Measurement of acceleration: a new method of monitoring neuromus- 
cular function. Acta Anaesthesiol Scand 1988; 32: 45-8.

10. Fuchs-Buder T, Claudius C, Skovgaard LT, Eriksson LI, Mirakhur RK, Viby-Mogensen J; 8th International Neuromuscular Meeting. Good clinical research practice in pharmacodynamic studies of neuromuscular blocking agents II: the Stockholm revision. Acta Anaesthesiol Scand 2007; 51: 789-808.

11. Pieters A, De Wolff M, Vanlinthout L. A comparison of mechanomyography and acceleromyography for the assessment of rocuronium induced neuromuscular block. Acta Anaesthesiol Belg 2002; 53: 85.

12. Kirkegaard-Nielsen H, Helbo-Hansen HS, Lindholm P, Pedersen HS, Severinsen IK, Schmidt MB. New equipment for neuromuscular transmission monitoring: a comparison of the TOFGuard with the Myograph 2000. J Clin Monit Comput 1998; 14: 19-27.

13. Söderström CM, Eskildsen KZ, Gätke MR, Staehr-Rye AK. Objective neuromuscular monitoring of neuromuscular blockade in Denmark: an online-based survey of current practice. Acta Anaesthesiol Scand 2017; 61: 619-26.

14. Carter JA, Arnold R, Yate PM, Flynn PJ. Assessment of the Datex Relaxograph during anaesthesia and atracurium-induced neuromuscular blockade. Br J Anaesth 1986; 58: 1447-52.

15. Katz RL. Comparison of electrical and mechanical recording of spontaneous and evoked muscle activity. The clinical value of continuous recording as an aid to the rational use of muscle relaxants during anesthesia. Anesthesiology 1965; 26: 204-11.

16. Engbaek J. Monitoring of neuromuscular transmission by electromyography during anaesthesia. A comparison with mechanomyography in cat and man. Dan Med Bull 1996; 43: 301-16.

17. Kopman AF. The dose-effect relationship of metocurine: the integrated electromyogram of the first dorsal interosseous muscle and the mechanomyogram of the adductor pollicis compared. Anesthesiology 1988; 68: 604-7.

18. Naguib M, Brull SJ, Kopman AF, Hunter JM, Fülesdi B, Arkes $\mathrm{HR}$, et al. Consensus statement on perioperative use of neuromuscular monitoring. Anesth Analg 2018; 127: 71-80.

19. Suzuki T, Fukano N, Kitajima O, Saeki S, Ogawa S. Normalization of acceleromyographic train-of-four ratio by baseline value for detecting residual neuromuscular block. Br J Anaesth 2006; 96: 44-7.

20. Kopman AF. Normalization of the acceleromyographic train-offour fade ratio. Acta Anaesthesiol Scand 2005; 49: 1575-6.

21. Liang SS, Stewart PA, Phillips S. An ipsilateral comparison of acceleromyography and electromyography during recovery from nondepolarizing neuromuscular block under general anesthesia in humans. Anesth Analg 2013; 117: 373-9.
22. Claudius C, Skovgaard LT, Viby-Mogensen J. Is the performance of acceleromyography improved with preload and normalization? A comparison with mechanomyography. Anesthesiology 2009; 110: 1261-70.

23. Murphy GS, De Boer HD, Eriksson LI, Miller RD. Reversal (antagonism) of neuromuscular blockade. editors. Miller's anesthesia. 8th ed. In: Miller RD, Philadelphia, Elsevier. 2015. p. 995-1027.e5.

24. Murphy GS, Szokol JW, Avram MJ, Greenberg SB, Shear TD, Deshur M, et al. Comparison of the TOFscan and the TOFWatch SX during recovery of neuromuscular function. Anesthesiology 2018; 129: 880-8.

25. Smith DC, Booth JV. Influence of muscle temperature and forearm position on evoked electromyography in the hand. Br J Anaesth 1994; 72: 407-10.

26. Nemes R, Diószeghy B, Pongrácz A, Tassonyi E, Fülesdi B. Performance assessment of a new electromyography-based neuromuscular monitor and subjective discomfort in unmedicated volunteers. J Anesth Clin Res 2018; 9: 848.

27. Bowdle A, Bussey L, Michaelsen K, Jelacic S, Nair B, Togashi K, et al. A comparison of a prototype electromyograph vs. a mechanomyograph and an acceleromyograph for assessment of neuromuscular blockade. Anaesthesia 2020; 75: 187-95.

28. Bowdle A, Bussey L, Michaelsen K, Jelacic S, Nair B, Togashi K, et al. Counting train-of-four twitch response: comparison of palpation to mechanomyography, acceleromyography, and electromyography. Br J Anaesth 2020; 124: 712-7.

29. Bussey L, Jelacic S, Togashi K, Hulvershorn J, Bowdle A. Trainof-four monitoring with the twitchview monitor electctromyograph compared to the GE NMT electromyograph and manual palpation. J Clin Monit Comput 2020 doi: 10.1007/s10877-02000615-7. [Epub ahead of print].

30. Nemes R, Nagy G, Murphy GS, Logvinov II, Fülesdi B, Renew JR. Awake volunteer pain scores during neuromuscular monitoring. Anesth Analg 2020; 130: 941-8.

31. Nemes R, Renew JR. Clinical practice guideline for the management of neuromuscular blockade: what are the recommendations in the USA and other countries? Curr Anesthesiol Rep 2020; 10: 90-8.

32. Seo HJ, Lee YK, Lee SS, Kim KS, Yang HS. A survey of postoperative residual neuromuscular block and neuromuscular monitoring. Anesth Pain Med 2010; 5: 70-4.

33. Kim JS, Han JW, Lee JH, Choi JM, Kim HJ, Sung TY, et al. Current use of neuromuscular blocking agents and antagonists in Korea: a 2018 survey. Anesth Pain Med 2019; 14: 441-8. 